\title{
Drainage System Overflow Pollutant Reduction of Stormwater Detention Tanks in Central Shanghai
}

\author{
Jiang CHENG ${ }^{1,2}$ \\ 1. State Key Laboratory of Estuarine \\ and Coastal Research \\ East China Normal University \\ Shanghai, China \\ sklec@qq.com
}

\author{
Wei PAN ${ }^{2}$, Min DING ${ }^{2}$ \\ 2. Technical Designing \& Research \\ Institute \\ Shanghai Municipal Sewerage \\ Company Ltd. \\ Shanghai, China
}

\author{
Panjun DU ${ }^{3}$ \\ 3. East China Sea Marine Forecasting \\ Center \\ State Oceanic Administration \\ Shanghai, China
}

\begin{abstract}
In order to control drainage system overflow pollutant during wet and dry seasons, five stormwater detention tanks (SDTs) were built along the Suzhou Creek in central Shanghai, China. The effect of SDTs on pollutant reduction was investigated based on the precipitation, storm runoff, pumping station discharge, SDT detention volume and drainage system overflow pollutant concentrations measured in 2012. The results show that: (1) The SDTs could reduce drainage system overflow pollutants effectively. The annual overflow water reduction rate was from $3.6 \%$ to $45.1 \%$, respectively, and the annual overflow chemical oxygen demand (COD) reduction rate was from $\mathbf{7 . 2 \%}$ to $62.9 \%$, respectively. (2) In the local physiographic conditions of precipitation characteristic, drainage system area and land use type, volume design standard of SDT was the most important factor to the overflow water and pollutant reduction rates of drainage system. (3) In order to make full use of the overflow water and pollutant reduction effects of SDT, the proper volume design standard was suggested in physiographic conditions mentioned above in central Shanghai, China.
\end{abstract}

Keywords-stormwater detention tank; overflow reduction; drainage system; Suzhou creek

\section{INTRODUCTION}

In cities with drainage system (separate sewer system and combined sewer system), receiving watercourses may be severely contaminated when the capacity of some pumping stations is exceeded as a result of storm runoff ${ }^{[1]}$. Many studies showed that surface water quality is negatively impacted by urban development due to pollutant loads in stormwater overflow $^{[2]}$. After the point sources pollution had been controlled welly, for the identification of significant pressures from non-point sources pollution on urban surface waters, it is necessary to reduce the pollution loads from urban areas, i.e. separate sewer system and combined sewer system stormwater overflows. As a useful low impacted development (LID) facility, the stormwater detention tanks (SDTs) were widely put into reducing drainage system overflow water and pollutants both in wet and dry seasons in developed countries such as Germany, United States, France, Spain and Japan ${ }^{[3,4]}$. For example, more than 13,000 combined sewer overflow control tanks have been built in Germany using the ATV 128 rule until 1998.

In central Shanghai, China, five SDTs were built along the Suzhou Creek during the two-stage Suzhou comprehensive environmental treatment project from 2003 to $2005^{[3]}$. Over the past several years, the researches about the environmental effects of SDT had focused on empirical estimation ${ }^{[5]}$, mathematical model assessment ${ }^{[6]}$, and environmental effect of single $\mathrm{SDT}^{[7]}$. And the systemic and comparatively research has not been carried out.

In this paper, in order to bring useful reference to SDT planning, design, construct, operating and management, and also to the non-point sources pollution control research, the comprehensive environmental effects of the five SDTs (CDL, XCP, MQY, JSL and FRJ SDT) were studied based on the continued stormwater runoff water quality, drainage system stormawter overflow water quality and the operating data of STDs.

\section{MATERIALS AND METHODS}

\section{A. Study area}

Normal annual rainfall was about $1,150 \mathrm{~mm}$ in central Shanghai, China. Approximately $70 \%$ precipitation was yield during the wet season (April to September) ${ }^{[8]}$. The study SDTs were located along the Suzhou Creek in central Shanghai. Table 1 was the introduction of the five SDTs.

Table 1 Introduction of five SDTs

\begin{tabular}{|c|c|c|c|c|c|}
\hline \multirow{2}{*}{ Parameters } & \multicolumn{5}{|c|}{ Name of STD } \\
\cline { 2 - 6 } & $\boldsymbol{C D L}$ & $\boldsymbol{X C P}$ & $\boldsymbol{M Q Y}$ & $\boldsymbol{J S L}$ & $\boldsymbol{F R \boldsymbol { J }}$ \\
\hline Operating year & 2007 & 2009 & 2011 & 2011 & 2012 \\
\hline System type & combined & combined & combined & combined & separate \\
\hline System area $\left(\mathrm{km}^{2}\right)$ & 3.06 & 3.45 & 2.96 & 3.77 & 6.83 \\
\hline $\begin{array}{c}\text { STD volume design } \\
\text { standard }\left(V_{S R}\right)\end{array}$ & 20.15 & 44.21 & 104.68 & 27.28 & 20.34 \\
\hline STD volume $\left(\mathrm{m}^{3}\right)$ & 7,400 & 15,000 & 25,000 & 10,800 & 15,000 \\
\hline Inlet model & pump & \multicolumn{5}{|c|}{ gravity flow } \\
\hline $\begin{array}{c}\text { Equipped pump ability } \\
\text { for inlet }\left(\mathrm{m}^{3} / \mathrm{s}\right)\end{array}$ & 4.090 & \multicolumn{5}{|c|}{} \\
\hline
\end{tabular}




\section{B. SDT volume design}

Volume design of the SDT used the ATV 128 rule in Germany. The volume of SDT can be expressed ${ }^{[5]}$ :

$$
V=1.5 \times V_{S R} \times A_{U}
$$

where $V$ is the volume of SDT $\left(\mathrm{m}^{3}\right) . V_{S R}$ is the detention runoff $\left(\mathrm{m}^{3} / \mathrm{hm}^{2}\right)$, with a value from 12 to 40 in Germany. $A_{U}$ is the impermeability area $\left(\mathrm{hm}^{2}\right), A_{U}=$ system area $\times$ runoff coefficient.

\section{SDT control}

All equipments of SDT were controlled by programmable logic controller (PLC). The control models of SDT could be divided into five, such as dry weather model, rainfall inlet model, full tank model, outlet model and stir cleaning mode. Fig. 1 was the flow chart and graph of SDT ${ }^{[5,7]}$.
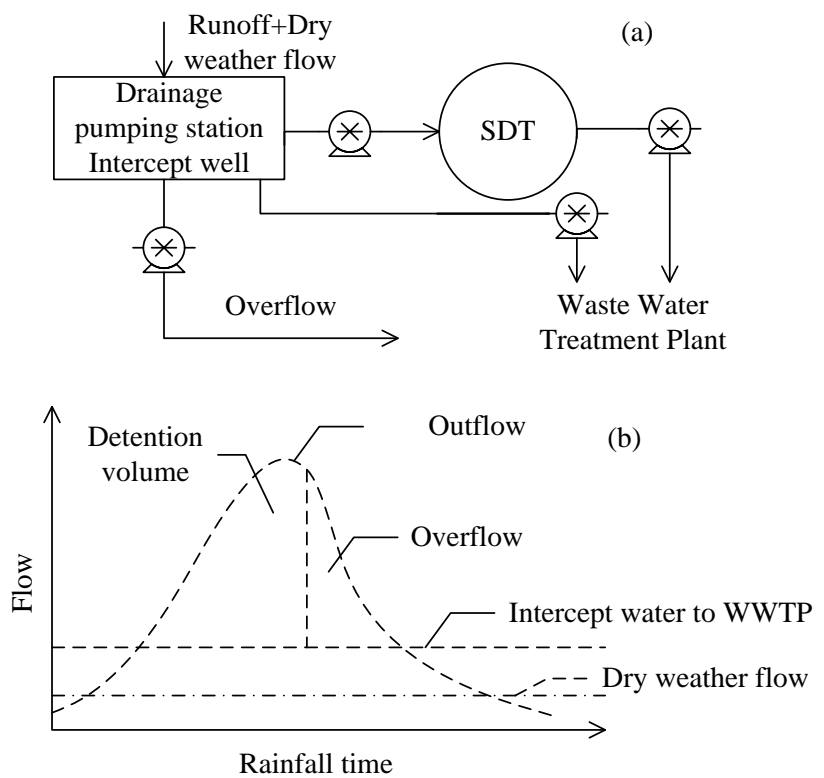

Fig. 1 Flow chart (a) and graph (b) of SDT

\section{Sample collection}

Sample collection of stormwater and overflow were carried out during 2012. The stormwater sampling method used in this study followed recommendations for stormwater discharge permits ${ }^{[9]}$. A Sigma 900 automatic sampling device set to the stormwater variable-intervals program was connected to the flow meter, which was programmed to send an alert signal to the automatic sampler when the flow reached $1.0 \mathrm{~m}^{3} / \mathrm{s}$. Once the sampling cycle had commenced, the samples were collected in 1-litre polyethylene bottles, the first six at 5-min intervals and the rest at 10-min intervals.

\section{E. Water quality analysis}

All samples were subjected to a complete physicochemical analysis using standard methods US EPA standard methods ${ }^{[10]}$. A total of 4 pollutants, i.e., COD, SS, $\mathrm{NH}_{4}{ }^{+}-\mathrm{N}$ and TP, were considered for this study.

\section{F. Data analysis}

The water quality analysis has been guided by the results of the US EPA Nationwide Urban Runoff Program Collection $(\mathrm{NURP})^{[11]}$. From the general findings of this project, we followed the main and still valid points:

In most cases the total runoff load is more important than the individual concentrations of particular parameters. This is due to the relatively short duration of runoff events (overflows) followed by mixing in the receiving waters. Therefore, the behaviour of the receiving waters is a response to the total loads rather than to the variable concentrations within each particular event. The NURP studies focused on evaluating EMCs, defined as the ratio of the mass of pollutants contained in a runoff event $(\mathrm{kg})$ to the total volume of flow in the event $\left(\mathrm{m}^{3}\right)$ :

$$
E M C=\frac{\sum Q_{i} c_{i} \Delta t_{i}}{\sum Q_{i} \Delta t_{i}}
$$

where $E M C$ is the Event Mean Concentration of a particular pollutant $\left(\mathrm{kg} / \mathrm{m}^{3}\right), Q_{i}$ is the discharge during time interval $i$ $\left(\mathrm{m}^{3} / \mathrm{min}\right), c_{i}$ is the concentration of pollutant during time interval $i\left(\mathrm{~m}^{3} / \mathrm{min}\right), \Delta t_{i}$ is the length of time interval $i$ (min).

\section{G. SDT efficiency calculation}

Total overflow volume reduction efficiency of SDT can be expressed:

$$
\text { Efficiency }=\frac{Q_{1}}{Q_{1}+Q_{2}}
$$

where $Q_{1}$ is runoff stored by SDT $\left(\mathrm{m}^{3}\right), Q_{2}$ is $\operatorname{CSO}\left(\mathrm{m}^{3}\right)$.

Total overflow pollutant mass reduction efficiency of SDT can be expressed:

$$
\text { Efficiency }=\frac{Q_{1} E M C_{1}}{Q_{1} E M C_{1}+Q_{2} E M C_{2}}
$$

where $Q_{1}$ is runoff stored by $\operatorname{SDT}\left(\mathrm{m}^{3}\right), Q_{2}$ is overflow $\left(\mathrm{m}^{3}\right)$, $E M C_{1}$ is the Event Mean Concentration of a particular pollutant stored by SDT $\left(\mathrm{kg} / \mathrm{m}^{3}\right), E M C_{2}$ is the Event Mean Concentration of overflow pollutant $\left(\mathrm{kg} / \mathrm{m}^{3}\right)$.

\section{RESULTS AND DISCUSSION}

\section{A. Precipitation}

Fig. 2 was precipitations of five drainage systems served by five SDTs during the 2012. The mean precipitation was about $1247.9 \mathrm{~mm}$, which was $8.5 \%$ larger than long-time average annual value, which was the broken line in Fig.2. 
Table 3 Overflow volume and COD reduction ratios in 2012

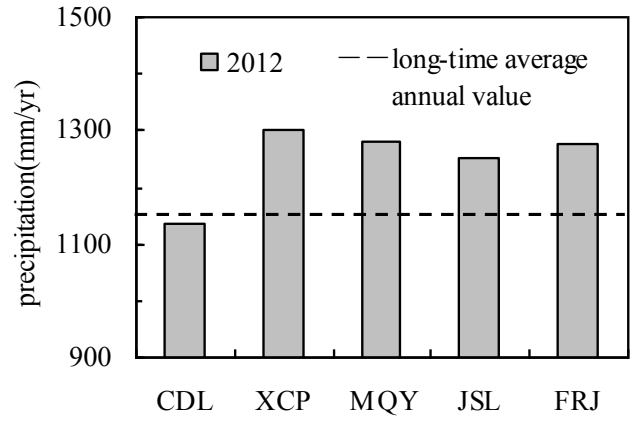

Fig. 2 Flow chart (a) and graph (b) of SDT

\section{B. Pollution concentration}

Storm runoff enters the drainage system during wet or dry weather. If the input exceeds drainage pumping station design flow, drainage system overflow will result. In addition, the runoff may itself increase the contaminant load, as a result of both (a) its own contaminant load, derived from urban surfaces, and (b) the erosion and wash-out of in-sewer sediments. Often, pollution graphs show a "first flush": In other words, contaminant load is particularly high during the early stages of the overflow event ${ }^{[12,13]}$. The EMCs for each drainage systems were calculated using Eq.3. Table 2 was the EMCs of each system. Because there exists "first flush" phenomena in all systems, so the COD EMC of runoff stored by SDTs were much higher than those of the overflow.

Table 2 Introduction of five SDTs

\begin{tabular}{|c|c|c|c|c|c|}
\hline \multirow{2}{*}{ COD EMC } & \multicolumn{5}{|c|}{ Name of STD } \\
\cline { 2 - 7 } & $\boldsymbol{C D L}$ & $\boldsymbol{X C P}$ & $\boldsymbol{M Q Y}$ & $\boldsymbol{J S L}$ & $\boldsymbol{F R \boldsymbol { J }}$ \\
\hline $\begin{array}{c}\text { Background of dry weather } \\
\text { flow (sewage) }\end{array}$ & 236 & 242 & 248 & 231 & 252 \\
\hline Detention water & 412 & 487 & 679 & 435 & 448 \\
\hline Overflow & 267 & 229 & 211 & 254 & 228 \\
\hline Background of Suzhou Creek & \multicolumn{5}{|c|}{18.6} \\
\hline V class surface water in China & \multicolumn{6}{|c|}{} \\
\hline
\end{tabular}

\section{Pollution reduction effeciciency of SDTs}

All calculations were made on a yearly basis. The year for which the analysis performed was 2012, which was a wet year but did not lead to any flooding or malfunctioning of technical infrastructures. The total COD reduction of five SDTs was 1,008.6 tons. Fig. 3 showed the COD reduction of each SDT.

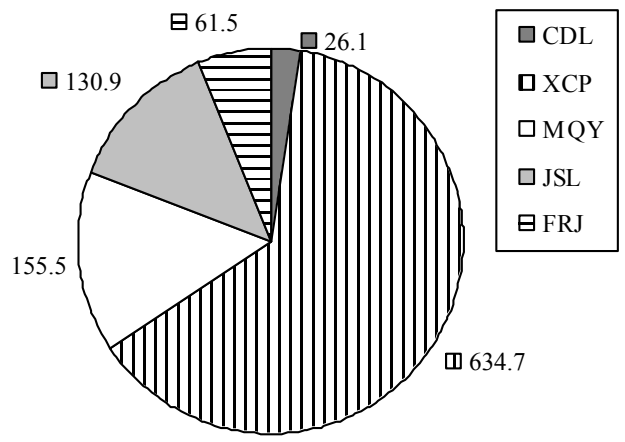

Fig. 3 COD reduction of five SDTs in 2012 (unit: ton)

\begin{tabular}{|c|c|c|c|c|c|}
\hline \multirow{2}{*}{ Parameters } & \multicolumn{5}{|c|}{ Name of STD } \\
\cline { 2 - 6 } & $\boldsymbol{C D L}$ & $\boldsymbol{X C P}$ & $\boldsymbol{M Q Y}$ & $\boldsymbol{J S L}$ & $\boldsymbol{F R \boldsymbol { J }}$ \\
\hline Precipitation (mm) & 1134.9 & 1299.9 & 1279.1 & 1250.5 & 1275.1 \\
\hline STD used times & 9 & 89 & 16 & 27 & 12 \\
\hline $\begin{array}{c}\text { Detention water } \\
\left(\times 10^{4} \mathrm{~m}^{3}\right)\end{array}$ & 5.3 & 129.0 & 31.6 & 26.6 & 12.5 \\
\hline Overflow $\left(\times 10^{4} \mathrm{~m}^{3}\right)$ & 141.4 & 157.2 & 79.4 & 164.8 & 248.4 \\
\hline $\begin{array}{c}\text { Overflow water } \\
\text { reduction ratio (\%) }\end{array}$ & 3.6 & 45.1 & 28.5 & 13.9 & 4.8 \\
\hline $\begin{array}{c}\text { Overflow COD } \\
\text { reduction ratio (\%) }\end{array}$ & 7.2 & 62.9 & 45.1 & 25.0 & 9.4 \\
\hline
\end{tabular}

According to Eq.4 and Eq.5, the annual overflow volume and COD reduction ratios were calculated. Table 3 presents the reduction ratios of five SDTs. Because of its larger volume, the XCP SDT had the better pollution reduction efficiency in overflow volume and COD. Its efficiencies were $45.1 \%$ and $62.9 \%$, respectively. This result can certainly help to prevent water pollution of receiving water bodies in urban areas.

\section{SDT volume design standard}

Based on the ATV 128 design rule in Germany, $V_{\mathrm{SR}}$ is a very important coefficient to overflow volume and pollutants reduction efficiency of SDT. When $V_{\text {SR }}$ with a value from 12 to 40 , the overflow efficiency of SDT which volume was designed using the ATV 128 rule in Germany is about $80 \%{ }^{[14]}$. In Calabró's research ${ }^{[15]}$, the simulations detention tanks demonstrated good performances in total suspended solids retention when $V_{\mathrm{SR}}$ with a value from 5 to 35 in Italy.

But in Shanghai, because of the precipitation characteristic is obvious different to those in Germany and Italy, when $V_{\mathrm{SR}}$ is about from 20 to 40 , the efficiency is about from $10 \%$ to $50 \%$ in this study, which is obvious lower than the efficiency in Germany and Italy. In order to get a good overflow volume and mass reduction efficiency, a proper $V_{\mathrm{SR}}$ about 100 and 110 should be chosen from Fig. 4 and Fig. 5, respectively, which is simulated from the real precipitation and drainage system overflow data from 2006 to 2012 in central Shanghai, China.

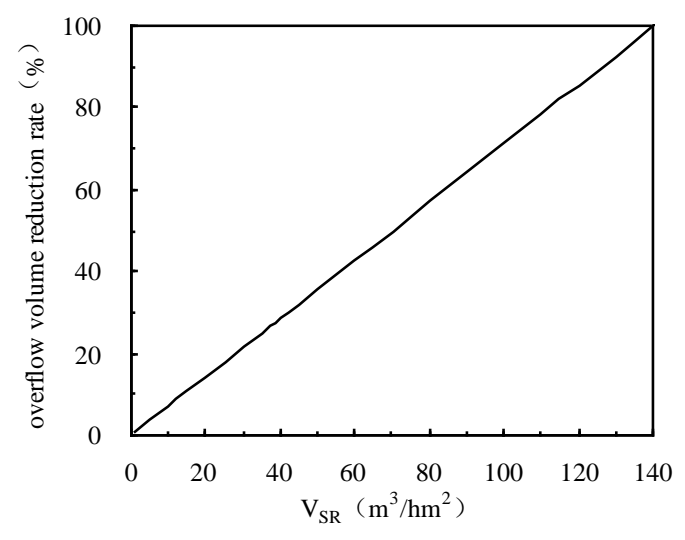

Fig. 4 Relationship between different $\mathrm{V}_{\mathrm{SR}}$ and stormwater overflow volume reduction rate in central Shanghai 


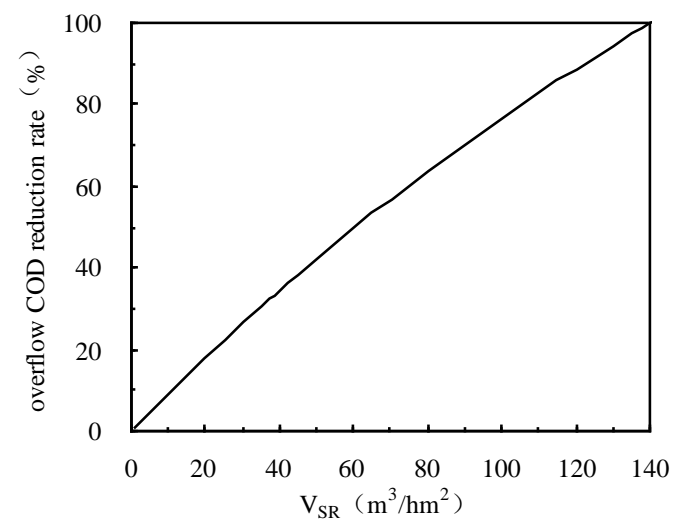

Fig. 5 Relationship between different $\mathrm{V}_{\mathrm{SR}}$ and stormwater overflow pollutant reduction rate in central Shanghai

\section{CONCLUSIONS}

The SDT was a useful facility to reduce drainage system overflow volume and pollutants in both wet and dry seasons. Case study showed that five different SDTs with $V_{\mathrm{SR}}$ from 20.15 to 104.68 had different overflow volume and mass reduction efficiency because of the different volume design standards.

The SDT volume design standard and rainfall characteristic are the important influencing factors to realize the environmental effects of SDT. In order to get a good drainage system overflow volume and mass reduction efficiency, a proper $V_{\mathrm{SR}}$ about 100 and 110 should be chosen in central Shanghai, respectively.

\section{ACKNOWLEDGMENT}

The authors are grateful to Senior Engineer Hua CHEN, Senior Engineer Shu-shi YUAN, Engineer Li ZHANG and Hong JIANG for the data collected.

This paper was financially supported by the grant from the Natural Science Foundation of China (NSFC) (Grant No. 51009068 and 41171017).

\section{REFERENCES}

[1] Diaz-Fierros F., Puerta J., Suarez J., et al. Contaminant loads of CSOs at the wastewater treatment plant of a city in NW Spain [J]. Urban Water, 2002, 4:291-299.
[2] Amir T., Ronald L.. Pollution loads in urban runoff and sanitary wastewater [J]. Science of the Total Environment, 2004, 327:175-184.

[3] Cheng J., Pan W., Ding M.. Initial rainwater pollutant reduction practice of urban drainage system in Shanghai City [A]. The International Conference on Remote Sensing, Environment and Transportation Engineering (RSETE 2011), June 24 to 26, 2011 in Nanjing, China. 4121-4124.

[4] Chen J.Y., Adams B.J.. Analysis of storage facilities for urban stormwater quantity control [J]. Advanced in Water Resources, 2003, 28:377-392.

[5] Zhang C.. Study of Overflow Storage technology of Combined Sewerage System and Analysis of Practical Example [J]. Urban Roads, Bridges \& Flood Control, 2006, 5:1-4. (In Chinese with English abstract)

[6] Xu G.Q., Chen C.T., Zhang H.Y.. Study on the influence of controlling pollution of the overflow from the initial rainwater storage tanks to Suzhou creek [J]. Advances in Water Science, 2006, 17(5):705-708. (In Chinese with English abstract)

[7] Cheng J., Lv Y.P., Huang X.F., et al. Environmental Effects of Combined Sewage Detention Tank in Central Shanghai [J]. Environmental Science, 2009, 30(8):2234-2240. (In Chinese with English abstract)

[8] Cheng J.,Yang K., Liu L.L.. Impact of 60 Years Land Use Change on Rainfall-Runoff in Central Shanghai [J]. Journal of Natural Resources, 2010, 25(6):914-925. (In Chinese with English abstract)

[9] Soonthornnonda P., Christensen E.R.. Source apportionment of pollutants and flows of combined sewer wastewater [J]. Water Research, 2008, 42:1989-1998.

[10] American Public Health Association (APHA). Standard methods for the examination of water and wastewater, 20th ed [S]. American Public Health Association (APHA)/American Water Works Association (AWWA)/Water Environment Federation (WEF), Washington, DC., 1998.

[11] US EPA. Results of the national urban runoff program. Final Report (Vol. 1) [R]. Washington, DC: US EPA Water Planning, 1983.

[12] Cheng J.,Yang K., Huang X.F., et al. Hydrology and Water Quality of Rainfall-Runoff in Combined Sewerage System Along Suzhou Creek in Central Shanghai [J]. Environmental Science, 2009, 30(7):1893-1890. (In Chinese with English abstract)

[13] Deletic A.. The first flush load of urban surface runoff [J]. Water Research, 1998, 32(8):2462-2470.

[14] Cheng J., Pan W., Ding M.. CSO Pollutants Reduction Effects of Two Different Stormwater Detention Tanks in Central Shanghai [A]. The International Conference on Remote Sensing, Environment and Transportation Engineering (RSETE 2012), June 2 to 4, 2012 in Nanjing, China. 401-404.

[15] Calabró P.S., Viviani G.. Simulation of the operation of detention tanks [J]. Water Research, 2006, 40:83-90. 